\title{
Building Resilient SCs: Mapping and Measuring Key Value Drivers through a Multi-perspective and Multi-stakeholder Value Creation Framework based on Intangible Assets
}

\author{
Stephane Pagano, Gilles Neubert \\ EMLYON Business School - UMR5600, \\ 23, avenue G. de Collongue, 69134 Ecully France \\ \{Pagano, GNeubert\}@EM-Lyon.com
}

\begin{abstract}
Until recently, the evolution of strategy and of business models mainly focused on shareholder Value Creation with global offshoring and outsourcing. The competitive cost models of globalized flows, translated in worldwide Supply Chains, with intensive energy consumption of fossil fuels and optimized processes with outsourcing to specialized agents, highly dependent on globalized infrastructures resources and markets. Our approach is that to build resilient companies and networks, all the stakeholders of the Supply Chain must be able to shift and align their perspectives, understand, map, value and document the key drivers that constitute the core competences needed, the appropriate intangible assets. Our proposition is a methodology to analyze, map and measure the key drivers of Value Creation through of multiperspective and multi-stakeholder framework, based on intangible assets.
\end{abstract}

Keywords: Value Creation, Collaborative ecosystems, Resilient SC, Intangible Assets, Stakeholders.

\section{Introduction}

In a rapidly changing environment, companies have to face many challenges while the competitive and technological environment keeps evolving at a fast pace: Globalization of markets through trade agreements and communication technologies, consumers' maturity and power of influence, strong trend towards a service-focused and dematerialized economy. Beyond a direct confrontation on their markets, with a particular focus on costs, firms have seen their competitiveness being challenged over new dimensions [1]. Consumers and non-profit organizations' pressure, legislation from states trying to limit externalities and reduce climate change impacts, real time information technologies being exploited by versatile consumers and investors. In a time where cost based competition remains harder and harder to maintain, the integration of stakes such as those addressed by Corporate Social Responsibility sets new standards for innovating strategies and competitiveness [2]. These concepts acknowledge that failing to do so inevitably leads to higher pressure from 
stakeholders, rising costs of environmental issues, and development of legal measures from states enforcing companies to share more of the value they create. All of these rising global risks on value creation, if not destroying value by rising sources of pressure on competitiveness.

The paper is organized as follow: after the introduction, the second part reviews essential concepts underlying our approach, the third part presents our framework and gives some details on our research and propositions. The fourth part presents some findings, while the conclusion draws expected contributions and future operational outputs.

\section{Context}

Today's value chains consist of globally spread stakeholders, globally spread production processes, global distribution and retail channels to reach clients. It is very fragile in essence, either because of geopolitical bottlenecks, environmental and social issues or because of natural disasters [3]. As part of the procurement process, the purchasing function is a fundamental hub for the firms, upstream of the Supply Chain, orchestrating and managing fundamental inputs in term of value creation, adapting to business models evolutions by configuring the SC to create and capture value.

\subsection{Value and Value Creation}

Value is a multi-perspective concept that extends beyond the limits of the firm. Globalization and technological innovation have reorganized the way value is created and delivered through dynamic networks or chains of interconnected firms or supply chain. This raises the question on how a particular relationship helps a firm creating value in terms of offerings, and what factor(s) are essential to successfully establish a particular relationship [4]. In a globalized Supply Chain, the strategic models of Value Creation based on arms-length confrontation with suppliers has led many companies on a short term value creation path, which meant value destruction for many suppliers and their economic ecosystem, impacting their entire value chain and their stakeholders. The value proposition is a strategic concept that allows firms to better analyze and describe their competencies and capacities, on the strategic as well as on the operational levels [5]. The deployment of the concept of Value Proposition had a significant impact on operational models of firms $[6,7]$.

To take into consideration these impacts, we position the Supply Management and the Supply Chain at the heart of the strategic models of firms.

\subsection{Corporate Social Responsibility}

There's an increasing pressure to consider the environmental and social aspects in purchasing policies: expectations are rising from stakeholders such as customers, the general public, NGOs, and governments who now hold companies responsible, not 
only for their own actions, but also all the partners within the supply chain $[8,9,10$, $11]$.

Corporate Social Responsibility is a concept that is becoming mainstream because it raises the question of establishing sound and balanced relationships between companies, a wider type of stakeholders, and their environment, at all different levels: global, regional and local, but also strategic, tactical and operational. CSR approach advocates the idea that companies need to change their business models and value propositions, actually integrating the idea of creating value not only for themselves, but also for a larger number of stakeholders. The Strategic Intention of the firm can practically be translated into strategic, tactical and operational actions.

The translation of this focus in the Supply Chain and the purchasing process reflects in a growing number of international recommendations and is now common in academics [12]. The focus on sustainability reporting initiatives and on CSR shows the necessity for companies to adopt a multi-perspective approach on the supplier selection and management: purchasing process and supply chain play a strategic role, which must go beyond optimization of processes, and take into account the temporal dimensions of the ROI (short, mid and long term) and the management of intangibles.

\subsection{Relationships and Risks Mitigation}

Usual competitive strategies based on competitive advantage, such as Porter's models [13] or Resource Based View [14], can't last. To address this issue, firms have investigated other domains: process optimization to save resources, flexibility, changes in relationship with other partners to secure exclusive access to suppliers because upsurge in globalized externalization and sourcing of trade, and the use of the Internet, has enlarged purchasers' accesses. Changes in organizational forms involve more decision-makers. These developments impact the complexity and importance of purchasing decisions $[15,16,17]$. Supplier management is a key issue in supply chain performances and this reflects in a continuing growth of publications [18, 19, 20, 21]. Since suppliers can represent up to $90 \%$ of firms turnover in industrial companies, the potential impact of inappropriate portfolio of suppliers can seriously impact the value of a company. The question of risks, systemic and global, predictable or not, strategic or external must be part of the strategy of firms [22].

At first, firms developed collaborative strategies, internal then between business units and departments, based on information sharing, and co-development of products and services. Instead of becoming experts, firms managed to collaborate with partners that could provide a competitive advantage [23]. Collaboration became a model for buyer-supplier relationship. Still, this remained in a narrow scope, without considering other stakeholders and that it's at a strategic level that is designed the Value Proposition for which the tactical and operational actions are translated. Firms are interconnected with their societal, natural and economic environment [24] thus depending on these in term of competitiveness: trained employees, infrastructures, communications, political stability. The state of the environment impacts the firms 
activity, the operational costs, the availability of the resources, and the value of the firms viewed by the stakeholders. Global environment is not just about financial crises and competitions: human operations and natural catastrophes can generate "future simultaneous shocks to systems (that) could trigger the 'perfect global storm', with potentially insurmountable consequences" [25]. These risks are putting a high pressure on companies that need to adapt rapidly to innovative or disruptive situations.

Companies, their suppliers and networks of partners need to be aligned to fulfill the strategy to deliver the value and adapt rapidly whatever challenge arises, and in this situation, a power relation may turn irrelevant if not destructive. To be resilient, companies and their networks have to build business ecosystems in a systemic thinking with relationships that are beyond transactional, with constant feedback, collaborative models, creating and extracting value in cascade and in interaction.

\section{Research Framework and Method}

The purchasing function is the architect of the globally spread value chain: many functions are now outsourced. In this regard, the value of the firm largely depends on the value purchased from the suppliers and appropriately delivered to internal customers, hence giving purchasing departments a fundamental role to build collaborative, cooperative and successful relationships both internally and externally.

\subsection{Focusing on Intangibles}

As we see it, creating value extends beyond the limits of the firm and must question the different dimensions and boundaries of the firm, their strategies and business models, what value they place at the heart of their value proposition and how they intend to create, capture and share value (figure 1). This requires considering internal organization of the firm, its networks of connections and partners, strategic models, its tangible and intangible assets and the notions of capital and investment. It is possible to comprise in the same model different values such as economic, financial, marketing but also intangible assets such as, management, services, strategic position or technical performance [26].

Though there is an abundant literature in economy and management on intangibles assets [27], we think that there is still a great work to do to operationalize intangible assets management with value creation for firms, according to a multi-perspective view, namely time frames, and according to a multi-stakeholder view, that is, in term of value created or destroyed by the firm for the different stakeholders in the firm's ecosystem. Our objective is to identify the value drivers in the organizational processes, going beyond the drivers already mastered by the buyers and more broadly the supply-chain: cost, quality, lead-time, financial performances and risk mitigation. The stake here is to demonstrate the contribution of intangible assets in the processes, seen here as drivers of successful relationships, by identifying their strategic 
importance in the interactions taking place in the processes. Finally, our applied research proposition is to build tools for the management of value creation in the buying and supply-chain processes that integrate these new perspectives.

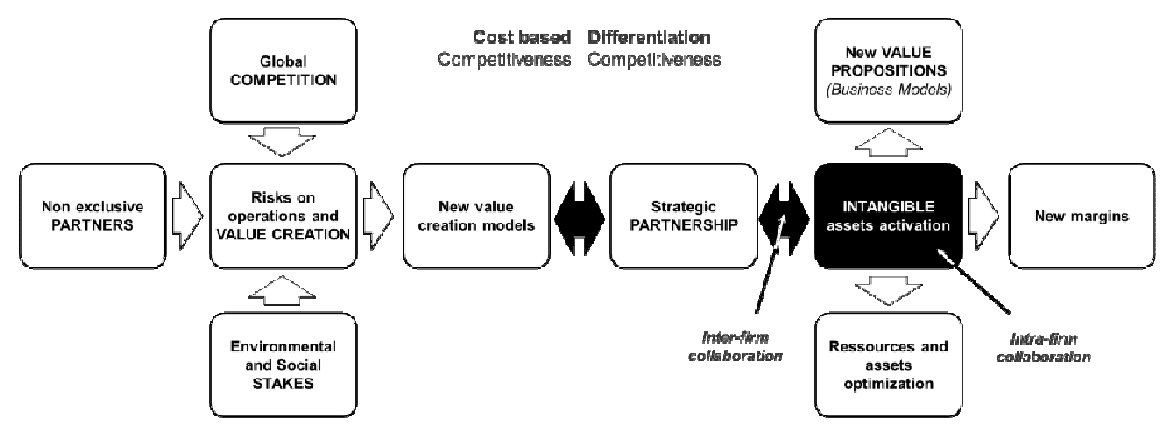

Fig. 1. Placing intangible assets at the heart of renewed value propositions.

Measure, management and value creation in the firm are spread over time and must take into account the stakeholders. To ensure the longevity of the firm, the following dimensions and perspective must be included in the processes:

- The time horizon of the firms' strategies;

- Value creation/destruction for the firm and its ecosystem;

- Actual place of intangible assets as drivers of competitiveness and value creation.

To achieve this, we are constructing on an approach by value "enablers" or "drivers" for future value creation [28], mapping intangible assets, processes and stakeholders through events that will eventually generate economic value and performance for the firm.

\subsection{Ground for the Research}

The global research ground for our projects is based on several companies operating in different industries. For this specific project, three companies offered the ground for initial explorations. Later on, among the three initial, two offered a long-standing participation for the conduct of the full research project for a period of two years.

- The first company, company A, is a food-products corporation operating on the global markets of waters, specialized nutrition and dairy products.

- The second company, company B, is an affiliate of the first, operating in France, specialized in dairy food and infant nutrition.

- The third company, company $\mathrm{C}$, is an international family-owned group, operating in 13 countries, specialized in aerolic and thermal systems for the building industry. 


\subsection{Empirical Method}

Our position is that "the organizational world is socially constructed" and that "the people constructing their organizational realities are knowledgeable agents (...) and can explain their thoughts, intentions, and actions" [29]. We build an iterative process where in each step, fieldwork confronts hypothesis and theory constructs elaborated on the previous ground observation. It borrows empirical investigation methodologies found in cases study methods specifically qualitative, in an interactive way so that the components of the research, i.e. purpose, context, questions, methods and validity of the research are always considered simultaneously at each step.

- The first step of the research is an exploration where we confront our initial question, "value creation \& collaborative relationships" to the stakeholders of the research ground. We state a hypothesis and test it.

- The second step, based on the findings of the precedent, is to reformulate the research question accordingly if need be, identify the underlying concepts, do literature reviews on these concepts, and go back on the ground to observe organizations and processes, through the lenses of the concepts, engaging in a near ethnographic approach.

- The third step is to build and share a conceptual framework where all the elements observed are connected to theories, build a methodology to gather and analyze qualitative data, and test the methodology with the stakeholders on the ground.

- The fourth step, where we are now, is to deploy the methodology in the field, refine it, collect data and code it in a dynamic way to avoid holes. This step is the core of the empirical investigation where different qualitative methods are interactively used: observation, interviews, questionnaires and documents analysis.

- The fifth and last step is two-fold: in terms of scientific research, we will have to decide which form will take the conclusion. In terms of applied research, we will negotiate on outputs that help companies that provided the ground to operationalize the scientific work.

\section{Main Outcomes}

As this research project is still ongoing, we only present partial findings from selected phases tested in the field. This communication wishes to present the research method, the principles of the practical output, and main outcomes of the empirical work.

\subsection{Initial Outcomes}

To initiate the research, we extended on a previous literature review on collaboration [26] and completed it with a literature review on value and on value creation. Then, we elaborated documents and presentations to share with the participating companies. Afterwards, we organized informal meetings with two groups of buyers from the three 
companies to share these views and gather some qualitative data regarding the proposed definitions and approaches.

The groups consisted in thirteen buyers from the company C, and two head of purchasing departments from companies A and B. These two meetings were conducted by asking open-ended questions to the audience and animating the discussions to gain insights. The initial open-ended questions were about the criteria used by the buyers and their managers to evaluate the success or the failure of a relationship with their suppliers.

While we were trying to find a pattern linking levels of collaboration and levels of (perceived) success, buyers seized the opportunity to focus on the fact that the "life" of the buyer-supplier relationship is as complex as any human based interaction between organizations and services, because, according to the buyers, it greatly relies on the "qualities" of the organization, carried and developed by persons of both sides of the relation (buyers, vendors, and other stakeholders involved).

We gathered structured data to complete the fuzzy findings of the meetings, by distributing formal surveys of the same questions, based on a pre-existing model [26] but providing this time precise criteria associated to likert-like scales. Buyers were asked to evaluate collaborative relationships criteria, for a relationship they estimated as successful, and for a relationship they estimated as failing. The results of criteria evaluation showed that certain collaboration criteria are consistently highly rated with a relationship considered as successful. On the opposite side, few criteria are consistently rated when it comes to failed relationships so buyers tend to have a more fuzzy perception, as far as criteria are concerned, of what characterizes a failed relationship.

The comments in the surveys were very consistent with the feedback from the meetings. In the cases of successful relationships, some buyers insisted in their comments on the facts that the personal behavior and skills of their corresponding contacts were the main reasons why they were satisfied with the relationship. In the cases of relationships considered as failing, it's the quality of the interpersonal relationships and organizational issues that were described.

Though in the same organization, each individual deals with a series of expectations and means to achieve them, according to different perception, interpretation and perspective. Participants proposed discussions based on their experience while we were biased trying to use a pre-conceived model: our assumptions assumed collaborative relationships meant successful relationships, which meant value creation. 


\subsection{Empirical Outcomes on the Tools Constructs}

To help companies in creating value through a multi-perspective and multistakeholder model, we are building a practical methodology to analyze and manage value creation in the processes, to objectively link the activation of intangible assets to value creation and achieve performance. At the heart of the methodology, we want to analyze the drivers represented by intangible assets (human capital, relational capital, structural capital) to connect them with the value proposition made to the clients.
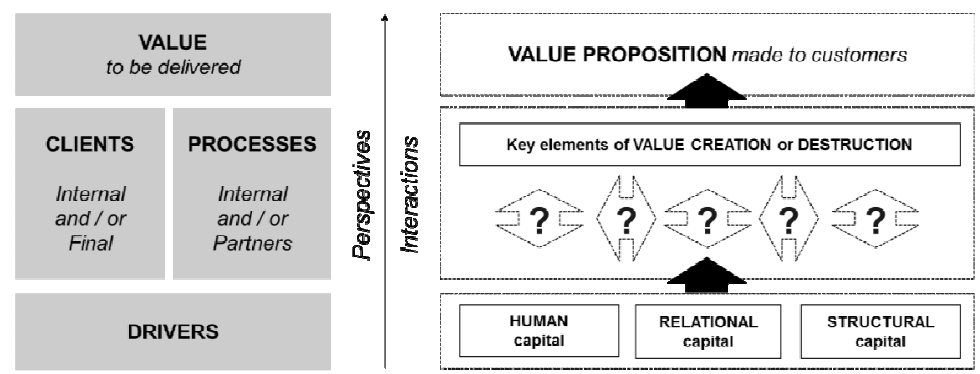

Fig. 2. The fuzzy box.

To do so, we need to clarify what happens in what we call a fuzzy box (figure 2) where players activate processes and stakeholders to achieve objectives and create value. Key steps here are to identify helping events occurring during the life of the project to evaluate the role and contribution of intangibles assets, and breaking events to capitalize on experience and construct feedback.

We have elaborated an interactive tool that allows the mapping, contextualization and linking of the stakeholders, their interactions and the value created or destroyed for each one of them (figure3).

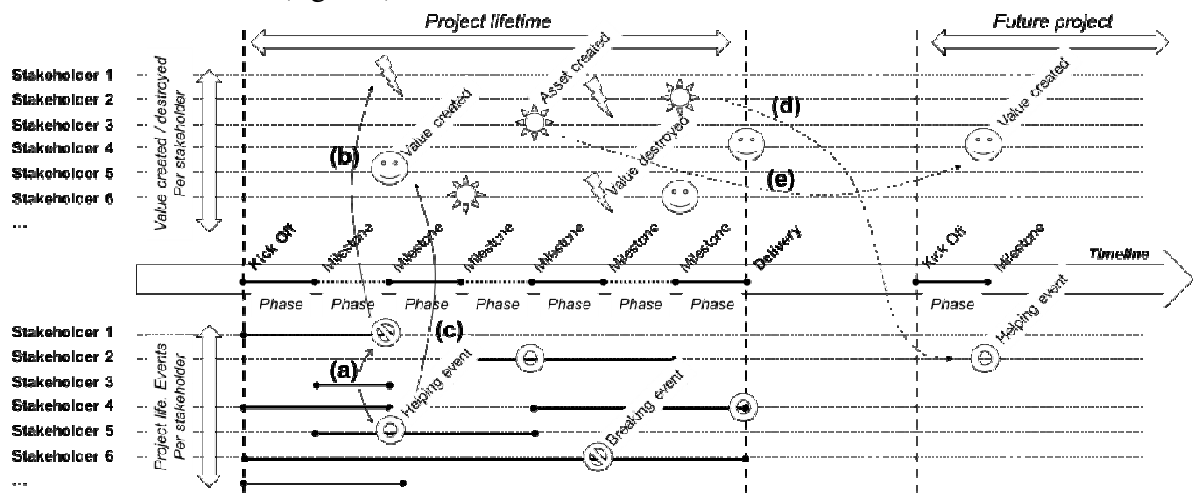

Fig. 3. Visual canvas, mapping events, value and stakeholders' interactions. 
Helping and breaking points of a given projects' life are positioned on timelines. Events' interactions (a) are visually mapped. It is possible to map the value destruction caused by breaking events (b) and value created by helping events (c). Assets created during one project can be identified as a significant source of a helping event in a future project (d), or directly create value (e). A concept that is at the core of our research work is that assets mobilized in one project are probably the result of a previous investment, just like assets generated in the current project can be drivers of future value.

To validate the method and the tools with the participating companies to the research project, we have organized a workshop with a team from each of the firms. The three teams add-up to a total of seven participants with varying profiles. To reinforce triangulation of this experience, we have asked the participating teams to bring to the workshop the story of a past project, that ended successfully or that failed.

All the team members found easy to list the stakeholders, to map the helping and breaking events, to connect the values generated, even though these values were outside of direct economic results, and to point value destructions for the different stakeholders. A very significant result is that the method offered the possibility to identify and map the ripple effects of the outcomes of a given project, allowing the affectation of more value to the global outcome of a project due to previously unaccounted dissemination to other projects. Comments were here that the method offered unsuspected outputs: some assets generated are reusable and thus multiplying their effects and value while remaining unaccounted or miss-affected. Value generated by one team could be capitalized by third parties without recognition of the original creators. Some assets generated by one project could be integrated in an innovative Business Models not foreseen before.

\section{Conclusion}

Two participating companies offered to follow one project each, during the full length of the projects. These two projects found their origin in the apparition of an important threat to their operations that needed urgent responses involving many internal and external stakeholders of their value and supply chain. When the incident or the pressure arises, the organizations temporarily reacts to respond to the issues in a resilient fashion: they appoint a project manager with appropriate credentials to mobilize all the departments of the company in a transversal team and mobilize the web of their partners, supply chain and value chain, to initiate multi-level tactical actions.

Their resiliency relies on an adaptive line:

- 1 Companies follow their normal operations;

- $\quad 2$ They get hit by a stressful event that impacts their operations and puts them at risk in term of viability; 
- $\quad 3$ They create a temporary structure, mobilizing the full web of internal and external stakeholders;

- 4 They elaborate a multi tactical strategy to have appropriate responses, deploy them to adapt or rebuild the necessary flows;

- 5 Once the response has been delivered and the crisis resolved, the temporary project structure is dissolved;

- 6 They return to their "normal" operations.

This ability for firms to adapt, reconfigure and respond, greatly relies on the capacity of the different stakeholders involved to collaborate and mutually adjust to each-others, diffuse information and realign. All this relies almost exclusively on the very own capacities of the actors involved (human, relational and structural capital), thus illustrating the central importance of intangible assets.

Very formalized processes can alter the adaptive capacities of companies and networks, building the case for a transversal, project based organization of processes and a qualitative approach of relationships and information sharing, all these heavily relying on the intangible assets of companies. Our objective is to identify the value drivers in the organizational processes, going beyond the drivers already mastered by the buyers and more broadly the supply-chain: cost, quality, lead-time, financial performances and risk mitigation.

While purchasing managers often apply methods focused on savings, a focus that limits their scope of action, participants to our research acknowledged positively our approach and identified intangible assets that could be drivers of the overall "value" created, because "any factor that enhances operational performance" and allows strategic alignment of the actors potentially generates "value". This is consistent with the literature review [26].

This research builds meaningful and applied methods to track, document and manage intangibles assets in response to internal or external pressure on value creation. It provides tangible and practical ways to objectivate very qualitative concepts all actors recon as essential to maintain and develop successful operations but have very few if no tools to leverage on in an environment governed by quantitative methods.

Expected outputs are: a tool to analyze the strategy of the firm and how it is translated along the supply chain, an analysis grid to identify and take into account all the stakeholders, a tool for mapping, contextualizing and linking the stakeholders, their interactions and the value created or destroyed for each one of them. These deliverables are being developed and refined through fieldwork.

Among scientific contributions, we expect this research will contribute to Resource-Based View theory, to Knowledge Management, to Sustainable Supply Chain and to Supply Chain performance. 


\section{Acknowledgements}

This project is part of the PEAK (Purchasing European Alliance for Knowledge). The authors would like to thank THESAME, the companies that co-finance this research project, and more generally the financial supporters of the PEAK program: member companies of the program, the F2I (Fund for Innovation and Industry) funding structure of the UIMM (Union of Metal Industries and Crafting), the UDIMERA (Rhône-Alpes' Union Of Metallurgical and Electrical Industries), the Research Division of the Regional Council of Rhône-Alpes, and the General Council of HauteSavoie which provides support to the Arve Industries competitiveness cluster.

\section{References}

1. Kim, W. and Mauborgne, R., 0. Value Innovation. Harvard Business Review, 82(7/8), 172180 (1997).

2. Lash, J., Wellington, F., Competitive Advantage on a Warming Planet. Harvard Business Review 85, 94-102 (2007).

3. Ambulkar, S., Blackhurst, J. and Grawe, S., Firm's resilience to supply chain disruptions: Scale development and empirical examination. Journal of Operations Management, 33-34, 111122 (2015).

4. Srivastava, V., Singh, T., Value creation through relationship closeness. Journal of Strategic Marketing 18, 3-17 (2010).

5. Martinez, V., Bititci, U.S., Aligning value propositions in supply chains. International Journal of Value Chain Management 1, 6-18 (2006).

6. O'Dell, C., Grayson Jr., C.J., Knowledge Transfer: Discover Your Value Proposition. Strategy \& Leadership 27, 10 (1999).

7. Bititci, U.S., Martinez, V., Albores, P., Parung, J., Creating and managing value in collaborative networks. International Journal of Physical Distribution \& Logistics Management 34, 251-268 (2004).

8. Jiang, B., The effects of interorganizational governance on supplier's compliance with SCC: An empirical examination of compliant and non-compliant suppliers. Journal of Operations Management 27, 267-280 (2009).

9. Kovács, G., Corporate environmental responsibility in the supply chain. Journal of Cleaner Production 16, 1571-1578 (2008).

10.Goebel, P., Reuter, C., Pibernik, R., Sichtmann, C., The influence of ethical culture on su plier selection in the context of sustainable sourcing. International Journal of Production Economics, Sustainable Development of Manufacturing and Services 140, 7-17 (2012).

11.Igarashi, M., de Boer, L., F et, A.M., What is required for greener supplier selection? A literature review and conceptual model development. Journal of Purchasing and Supply Management 19, 247-263 (2013).

12.Linton, J., Klassen, R. and Jayaraman, V., Sustainable supply chains: An introduction. Journal of Operations Management, 25(6), 10751082 (2007).

13.Porter, M.E., Competitive advantage: creating and sustaining superior performance: with a new introduction, 1st Free Press ed. ed. Free Press, New York (1998).

14.Barney, J., Firm Resources and Sustained Competitive Advantage. Journal of Management 17, 99 (1991). 
15.De Boer, L., Labro, E., Morlacchi, P., A review of methods supporting supplier selection. European Journal of Purchasing \& Supply Management 7, 75-89 (2001).

16.Weele, A.J. van, Purchasing \& supply chain management: analysis, strategy, planning and practice. Cengage Learning, Andover (2010).

17.Oshri, I., Kotlarsky, J., Willcocks, P.L.P., The Handbook of Global Outsourcing and Offshoring. Palgrave Macmillan (2011).

18.Ho, W., Xu, X., Dey, P.K., Multi-criteria decision making approaches for supplier evaluation and selection: A literature review. European Journal of Operation-al Research 202, 16-24 (2010).

19.Cao, M., Zhang, Q., Supply chain collaboration: Impact on collaborative advantage and firm performance. Journal of Operations Management 29, 163-180. (2011).

20.Wu, C., Barnes, D., A literature review of decision-making models and approaches for partner selection in agile supply chains. Journal of Purchasing and Supply Management 17, 256-274 (2011).

21.Chai, J., Liu, J.N.K., Ngai, E.W.T., Application of decision-making techniques in supplier selection: A systematic review of literature. Expert Systems with Applications 40, 38723885 (2013).

22.Kaplan, R.S., Mikes, A., Managing Risks: A New Framework. Harvard Business Review 90, 48-60 (2012).

23.MacCormack, A., Forbath, T., Learning the Fine Art of Global Collaboration. Harvard Business Review 86, 24-26 (2008).

24.Porter, M.E., Kramer, M.R., The Competitive Advantage of Corporate Philanthropy. Harvard Business Review 80, 56-69 (2002).

25.Howell, W.L., World Economic Forum. Risk Response Network, Global risks 2013. World Economic Forum, Cologny/Geneva, Switzerland (2013).

26.Parung, J., Bititci, U.S., A metric for collaborative networks. Business Process Management Journal 14, 654-674 (2008)

27.Sveiby, K.-E., Methods for Measuring Intangible Assets [WWW Document]. URL http://www.sveiby.com/articles/IntangibleMethods.htm (accessed 5.16.14).

28.Marr, B., Schiuma, G., Neely, A., Intellectual capital - defining key performance indicators for organizational knowledge assets. Business Process Management Journal 10, 551-569 (2004).

29.Gioia, D., Corley, K. and Hamilton, A., Seeking Qualitative Rigor in Inductive Research: Notes on the Gioia Methodology. Organizational Research Methods, 16(1), 1531. (2012). 